\title{
THE HARDENING IN ALLOYS AND COMPOSITES AND ITS EXAMINATION WITH A DIFFRACTION AND SELF-CONSISTENT MODEL
}

\author{
Elżbieta Gadalińska ${ }^{1 *}$, Andrzej Baczmański ${ }^{2}$, Sebastian Wroński², \\ Mirosław Wróbel $^{3}$, Christian Scheffzük ${ }^{4,5}$ \\ ${ }^{1}$ Institute of Aviation, Warsaw, Poland \\ ${ }^{2}$ AGH-University of Science and Technology, WFiIS, Kraków, Poland \\ ${ }^{3}$ AGH-University of Science and Technology, WIMiIP, Kraków, Poland \\ ${ }^{4}$ Frank Laboratory of Neutron Physics, \\ Joint Institute for Nuclear Research, Dubna, Russia \\ ${ }^{5}$ Karlsruhe Institute of Technology, AGW, Karlsruhe, Germany \\ "Elzbieta.gadalinska@ilot.edu.pl
}

\begin{abstract}
The paper presents the results of diffraction stress measurement in Al/SiC composite and in 2124 T6 aluminum alloy during the in situ tensile test. The main aim of the work is to observe the stress values for different stages of tensile test for the composite after applying two types of thermal treatment and for the alloy used as a matrix in this composite, to identify the type of hardening process. The experimental results were compared against the calculations results obtained from the self-consistent model developed by Baczmański [1] - [3] to gain the information about the micromechanical properties (critical resolved shear stress $\tau_{c r}$ and hardening parameter $H$ ) of the examined materials. This comparison allowed researchers to determine the role of reinforcement in the composite as well as the impact of the heat treatment on the hardening of the material.
\end{abstract}

Keywords: metal-matrix composites (MMCs), hardening, micro-mechanics, neutron diffraction

\section{INTRODUCTION}

A number of different factors affect the mechanism of hardening of alloys and composites: the phase composition, alloying agents, density of dislocation, morphology of precipitations resulting from a heat treatment applied or the grain 
size, and, naturally, the presence of reinforcement in composites [3]. Each of the above mentioned determinants influences the ability to move dislocations, which in turn changes the value of the yield strength and the ductility of the material. Firstly, the strengthening mechanisms, both in the alloy and in the composite of two types will be described. Then, the experimental setup will be specified and the experimental results will be discussed. This make it possible to determine the type of hardening in the composites examined.

\subsection{Hardening in alloys}

This chapter presents the equations for the resolved shear stress values under different circumstances with various factors taken into account.

The hardening of the alloy due to the presence of alloying elements is usually not very influencing and can play an important role only if its clusters are formed in the body of the material. Designating the distance between the clusters of alloying elements as $l$, let's assume that each cluster contains $n$ atoms, so the slip plane covered by the cluster is equal to $n b^{2}$, where $b$ is the vector of Burgers' displacements. Under these assumptions, the concentration of foreign atoms in the cluster will be [4]:

$$
c=\frac{n b^{2}}{l^{2}}
$$

The atoms of every cluster constrain the movement of dislocations in the slip plane and force the deflection. If the load applied rises, the deflection radius decreases while the force acting on every cluster increases. When assuming $r=\frac{l}{2}$ as the condition for the passing of the dislocation through the cluster, the shear stress will be [4]:

$$
\tau_{s}=\frac{2 \mu b}{l}
$$

where $\mu$ is the shear modulus.

The increase in critical resolved shear stress (CRSS) will be the result of eq. 1 and eq. 2 combined:

$$
\Delta \tau=2 \mu \sqrt{\frac{c}{n}}
$$


The grain size is another factor affecting the strength of alloy. The impact of this factor is ruled by the empirical relationship i.e. the Hall-Petch equation:

$$
\sigma_{y}=\sigma_{i}+\frac{k_{y}}{\sqrt{d}}
$$

where:

$\sigma_{i}-$ an average yield stress of a single grain,

$k_{y}$ - the effectivity of impact made on the yielding point by the grain boundaries (most commonly: 0.1MPa $\sqrt{m}$ [5]),

$d$ - average grain size.

The precipitation hardening involves a wide range of structural phenomena developing in metal alloys. The heat treatment such dissolution, solution heat treatment and aging causes the particles in the alloy to harden. During the aging process, stable and metastable phases precipitate, which in turn gives different hardening effects [6]. The mean CRSS value becoming from the spheroidal, coherent inclusion into the metal matrix, whose volume is bigger than the molar volume of the matrix, is given by [4]:

$$
\tau=2 \mu_{0} \varepsilon f
$$

where:

$\mu_{0}$ - the shear modulus of a matrix,

$\varepsilon$ - the precipitate - matrix misfit degree,

$f$-volume fraction of precipitates in the matrix.

If the distance between the precipitates in the slip plane is bigger than the minimal curvature radius $(\varrho)$ of the dislocation deflection [4]:

$$
\varrho=\frac{b}{4 \varepsilon f}
$$

the eq. 5 determines the macroscopic yield stress of a material.

If precipitate is supposed to affect the dislocation movement, the distance between precipitates $(d)$ must meet the requirement that:

$$
d \geq \frac{b}{4 \varepsilon f}
$$

The value of the critical resolved shear stress, required to move the dislocation through the coherent spherical precipitation particle, is given by: 


$$
\tau \geq \frac{f \gamma_{p}}{b}+\frac{\sqrt{6} f \gamma_{s}}{\pi r}
$$

where:

$\gamma_{\mathrm{p}}-$ the inner precipitate boundary energy (after the dislocation passing),

$\gamma_{\mathrm{s}}$ - the interphases (precipitate and matrix) boundary energy,

$r$-average radius of spherical precipitate.

The first term of eq. 8 relates to the stress necessary to shear the precipitate. When the precipitate size increases, this term becomes dominate. The second term expresses the stress needed for producing an extra interphase boundary between the precipitate and the matrix [4].

Above case describe the case of precipitate for which on the boundary the planes and crystallographic directions are preserved, known as the coherent precipitate. Not coherent particles are introduced into the material intentionally through the process of dispersion hardening to strengthen the material. In this case, the dislocations movement is explained by the Orowan approach. According to this concept, dislocations can pass through the particles leaving circular loops around them if the applied stress is high enough. In this situation, the shear stress is given by [4]:

$$
\tau=\tau_{s}+\frac{\mu_{0} b}{4 \pi} \Phi \ln \left(\frac{d-2 r}{2 b}\right) \frac{2}{d-2 r}
$$

where:

$\tau_{s}$ - matrix yield stress,

$\Phi=\frac{1}{2}\left[1+\frac{1}{(1-v)}\right]$ and $v$ - Poisson's ratio,

$d$ - average distance between particles in the slip plane,

$r$ - spheroidal particle radius.

\subsection{Hardening in metal matrix composites}

In the case of the metal matrix composites, both phenomena described above can appear, i.e. these characteristic for precipitates in alloys as well as in materials with particles intentionally introduced. The strengthening mechanisms can be generally divided into two groups from the perspective of the plasticity beginning: joined with the internal stresses and connected to the matrix microstructure effects. The first type is associated with not uniform stress distribution between the reinforcement and the matrix. It causes change in stress level in the matrix as compared to the material with the reinforcement when the same stress is applied. 
The effects connected with the microstructure of the matrix are: the evolution of dislocations, grain size of the matrix as well as the effects connected with the dispersive hardening [3].

\section{Internal stresses}

A relatively higher stiffness of the reinforcement particles as compared to the properties of the matrix causes the irregular distribution of stress applied to the material between the matrix and the reinforcement. Due to this phenomenon, the stress distribution is different in certain specific areas and points in the matrix. The reason is that, in the presence of the reinforcement, a very significant decrease in stress in the matrix appears as a result of load transfer from the matrix to the reinforcement. As the material has to fulfill the continuum conditions, the normal stress value on the interface reinforcement inclusion and the matrix have to be equal to the average stress value in the inclusion. On the other hand, experiments show that the yield stress of the composite material is not governed by the micro-yielding on the interface inclusion and matrix but rather by the achievement of the average stress value for the matrix [3], [7].

\section{Matrix microstructure effects}

The influence of the reinforcement on the strength of a composite as a whole is of bifold types. It affects the changes in the stress distribution but also the microstructural properties of the matrix.

The first type of composite hardening has the same origin as in the case of alloys: it is connected to the precipitations presence. Dislocations in metal matrix composites may have the origin of two types: in the load applied or in relaxation of residual thermal stresses. The case of residual thermal stresses was investigated by Arsenault et al. in [8] and [9]. The authors stated that the increase of dislocation density $\Delta \rho$ (as an outcome of punching of dislocation loops), could be described by the equation [7]:

$$
\Delta \rho=\frac{\Delta \alpha \Delta T \cdot N \cdot A}{b}
$$

where:

$\Delta \alpha$-difference between thermal expansion coefficients of phases in the composite, $\Delta \alpha \Delta T$ - thermal misfit strain,

$N$ - number of particles,

$A$ - total surface area of each particle,

$b$ - Burgers vector.

It follows from the above equation that the dislocation density increases with the reduction of reinforcement particle size. The effect is significant especially for particles whose size is below $1 \mu m$. 
The change in the matrix strength combined with the dislocation density is given by [7]:

$$
\Delta \sigma_{Y M} \sim G b \sqrt{\rho}
$$

The other source of the composites strengthening is associated with the grain size. Its influence on the composite strength is given by the classical HallPetch formula (eq. 4). This formula relates the change in the yield stress to the grain size. Substituting to the eq. 4 the appropriate values, i.e. $k y=0.1 M P a \sqrt{m}$ and $d=1 \mu \mathrm{m}$, the change in yield stress being the result of the fine grain size is about 100MPa. Clyne and Withers [7] suggest that in practical cases it is few tens of MPa [7].

The last type of the MMC composites' strengthening described by Orowan, is caused by the resistance of the dislocation through the tightly positioned particles of reinforcement. In the MMC, sizes of reinforcement particles are relatively big and distances between them are large so this mechanism can be treated as negligible. It can, however, play a role in age-hardened materials where precipitates in the matrix appear. On the other hand, the impact of the reinforcement on the size and distribution of fine precipitates can be significant [7].

\section{EXPERIMENT}

\subsection{Material}

The material used for the experimental investigation of strengthening mechanisms in metal matrix composites was an aluminum alloy matrix with a silicon carbide reinforcement; $\mathrm{Al} / \mathrm{SiC}$ composite. Aluminum is a material of relatively low density and strength but with high ductility and thermal and electrical conductivity [10]. It is relatively easy to form [11], [12]. The limitation for pure aluminum application is defined by its comparably low strength, hardness, melting point $\left(658^{\circ} \mathrm{C}\right.$ [13]), stiffness and tribological properties [10], [14]. However, strength and hardness can be easily improved by alloying and heat treatment via solution hardening or/and the second phase hardening (e.g. precipitation hardening of $\mathrm{Al}-\mathrm{Cu}$ alloys or silicon carbide particles hardening). The composite reinforced with the $\mathrm{SiC}$ particles was chosen for these investigations, because of significance of this kind of composites in the space-aviation applications [15].

The material examined in this work was produced by Materion Company with a unique method known as the BP process. This technique involves blending and compaction of mixed powder components [16]. Thanks to that technique the resulting composite possesses better mechanical properties, which is the main advantage of this method. These superior properties result from improved strength 
at the matrix/reinforcement interface [16]. The examined composite was combined from the 2124 aluminum alloy matrix and the $\mathrm{SiC}$ particles reinforcement. The chemical composition of the alloy used is given in Table 1. The amount of the reinforcement particles in the examined composite was $17.8 \%$ by volume while the average size of particles was $0.7 \mu \mathrm{m}$. The composite was subjected to two different heat treatments: T1 and T6 to compare the ways in which the heat treatment methods on change the strengthening of the material [3].

\begin{tabular}{|c|c|c|c|c|c|c|c|c|}
\hline $\boldsymbol{C u}$ & $\boldsymbol{M g}$ & $\boldsymbol{M n}$ & $\boldsymbol{T i}$ & $\boldsymbol{Z n}$ & $\boldsymbol{C r}$ & $\boldsymbol{F e}$ & $\boldsymbol{S i}$ & $\boldsymbol{A l}$ \\
\hline 4.18 & 1.46 & 0.52 & 0.15 & 0.25 & 0.1 & 0.3 & 0.2 & balance \\
\hline
\end{tabular}

Table 1 Chemical composition of Al2124 alloy (mass fraction, \%) [17]

The composite after the $\mathrm{T} 1$ heat treatment was its soft version. It was annealed at $491^{\circ} \mathrm{C}$ for $6 \mathrm{~h}$, cooled in the air in normal conditions and naturally aged to a substantially stable condition [3].

The hard material, was subjected to T6 heat treatment, i.e. it was solution treated at $491{ }^{\circ} \mathrm{C}$ for $6 \mathrm{~h}$ and then water quenched and artificially aged for $4 \mathrm{~h}$ at $191{ }^{\circ} \mathrm{C}$. As a result of this treatment the $\mathrm{Cu}-\mathrm{Al}-\mathrm{Mg}$ precipitates appeared. After the solution heat treatment, the material was rapidly cooled to obtain solid solution supersaturated by alloying elements. The last step was the aging process, in which the dispersed particles precipitate from the supersaturated solution. For the purposes of comparison, the in situ diffraction was performed during tensile test for the pure 2124 aluminum alloy specimen after the same type of heat treatment (T6) [3].

The main difference between $\mathrm{T} 1$ and $\mathrm{T} 6$ material variants is the appearance of different types and sizes of precipitations. As a result of the T1 treatment, the thermodynamically stable, relatively large S-phase particles with chemically incoherent $\mathrm{Al}_{2} \mathrm{CuMg}$ are formed. On the other hand, the $\mathrm{T} 6$ treatment leads to the emergence of small metastable semi-coherent $\Sigma$ particles. This phenomenon is typical for $2 \mathrm{X} 24$ aluminum alloys in which the mass ratio of $\mathrm{Cu}$ to $\mathrm{Mg}$ varies from 2.1 to 4 [17]. The above mentioned precipitations are considered as to cause locking dislocations disabling slipping on crystallographic planes and hindering plastic process in the material when tensile forces are applied. The input of this mechanism, i.e. precipitation hardening, into the material hardening has been investigated in this work [3]. 


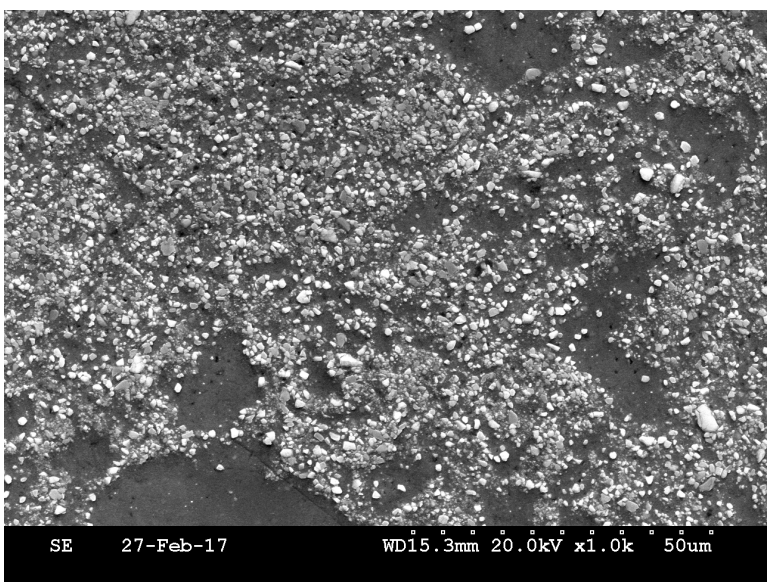

a)

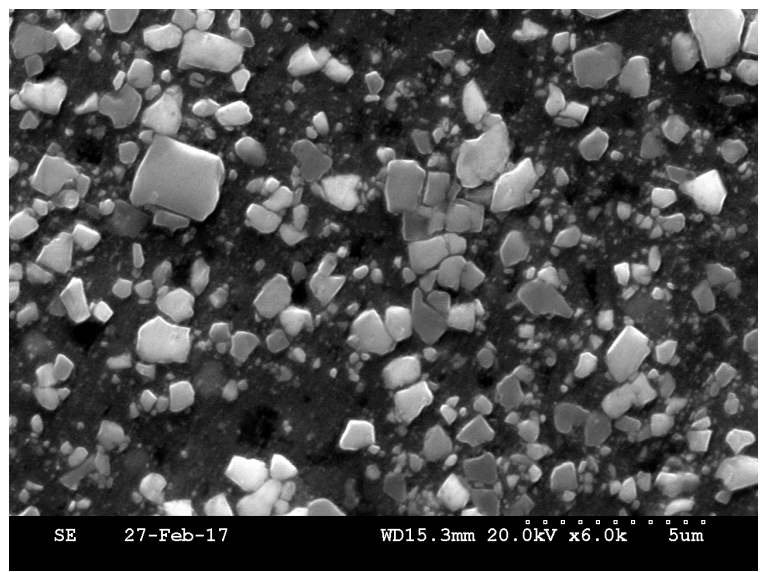

b)

Fig. 1 The SEM images of Al/SiCT6 composite. SiC particles are shown with white contrast.

The magnifications used for depicting were 1000 times in a) and 6000 times in b) [3]

In Fig. 1, the SEM pictures of hard specimen (Al/SiCT6) are presented, for different magnifications. The first observation is that the reinforcement particles are not distributed perfectly homogenously. On the other hand, in some approximation, the uniform particles' distribution can be presumed. It is worth mentioning that some dispersion of the particles size can be observed (although the nominal particle size is $0.7 \mu \mathrm{m}$ ).

The pole figures of both phases in $\mathrm{Al} / \mathrm{SiC}$ material were measured with the Panalytical Empyrean diffractometer with a $\mathrm{Cu} \mathrm{X}$-ray tube for which radiation wavelengths were: $\mathrm{K}_{\alpha 1}=1.54056 \AA, \mathrm{K}_{\alpha 2}=1.54439 \AA$. Because the texture is insignificant random ODFs were assumed for $\mathrm{Al}$ and $\mathrm{SiC}$. 


\subsection{The setup of diffraction measurements}

The diffraction experiments with the neutron radiation were performed at the Frank Laboratory of Neutron Physics, Joint Institute for Nuclear Research in Dubna (Russia) on the EPSILON MDS diffractometer designed for stress/strain measurements.

The experiment was performed with the Time-Of-Flight (TOF) method which is a type of energy dispersive method. The neutrons' beam applied was polychromatic, i.e. formed by the neutrons of different energies. This method allows applying Bragg's law to different lattice planes at a fixed scattering angle, typically $\theta=90^{\circ}$. The concept of this method involves measuring the time of flight of the neutrons over a given distance instead of measuring the diffraction angle [3]. The calculations of the interplannar spacings for given $h k l s$ are based on the combination of the de Broglie equation and Braggs' law:

$$
d_{h k l}=\frac{h t}{2 \sin \theta m_{n} L}
$$

where:

$m_{n}-1.675 \cdot 10^{-27} \mathrm{~kg}$ is the neutron mass,

$h-6.63 \cdot 10^{-34} \mathrm{~J} \cdot \mathrm{s}-$ Planc's constant,

$t$ - time of flight of the neutron from its source to the detector,

$\theta$ - Bragg's angle,

$L$ - the total distance between the neutron source and the detector; for

EPSILON-MDS it is $107.03 \mathrm{~m}$.

After a substitution into this equation all known values, including parameters characterizing the unique instrumentation in JINR in Dubna, the interplanar distance turns out to be dependent only on the time of flight of the neutrons $(t)$ :

$$
d=1.849 \cdot t[n m]
$$

The conclusion is that the time of flight of the neutrons can be directly used for the measurement of interplanar spacings in the specimen examined [3].

The specimen geometry, the measurement setup and the specimen pictures are presented in Fig. 2a-d. The measured gauge length was $15 \mathrm{~mm}$ and its cross section was $4.4 \mathrm{~mm} \times 4.4 \mathrm{~mm}$. The specimens were fixed in a tensile machine, located in the goniometer and subjected to the tensile test until fracture. The experiments were executed during the course of in situ tensile test whose objective was to measure $\mathrm{d}_{h k l}$ and resulting strains and stresses for different stages of macrostrain. To achieve these goals the diffraction measurements were performed for a few stages of the specimen deformation: in case of the hard specimen it was 
6 stages while in case of soft one it was 9 stages. The residual state of both specimens was measured for the initial state of specimens and after they fractured. The in situ tensile test ( 8 stages of deformation, initial and residual state) was also performed for the specimen prepared from the material used as a matrix in the $\mathrm{Al} / \mathrm{SiC}$ composite i.e. Al2124T6 alloy [3].

The data resulting from the experiments were gathered with two detectors' sets in order to measure lattice strains in two directions: in direction of the force applied, parallel to the axis of the specimen, and in the perpendicular direction (see detectors 2 and 8 in Fig. 2 b, for which the diffraction angle was $2 \theta=90^{\circ}$ ). The values of interplanar spacings $d_{h k l}$ were measured simultaneously for different $h k l$ reflections. As showed in the exemplary diffractogram $d_{h k l}$ values ranged between $0.8-2.7 \AA$. It covered reflections from both phases of $\mathrm{Al} / \mathrm{SiC}$ composite (Fig. 3). The incident beam was $10 \mathrm{~mm}$ wide and the time of one exposure was 22 - 23 hours for every specimen and every stage of its deformation [3].

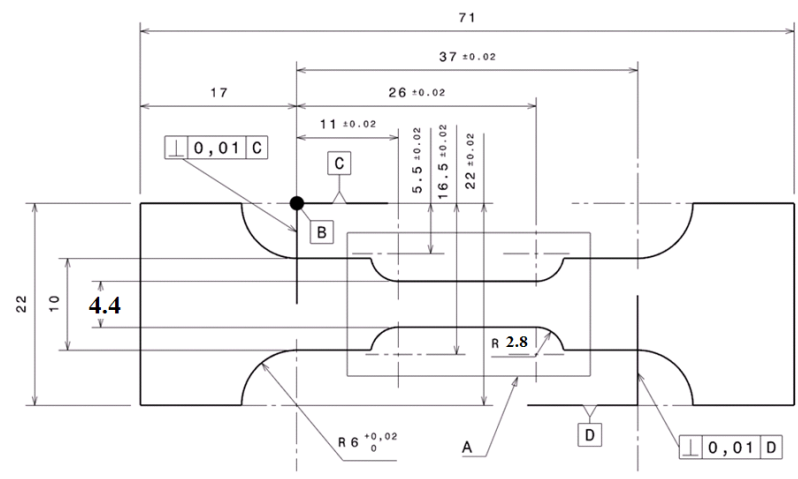

a)

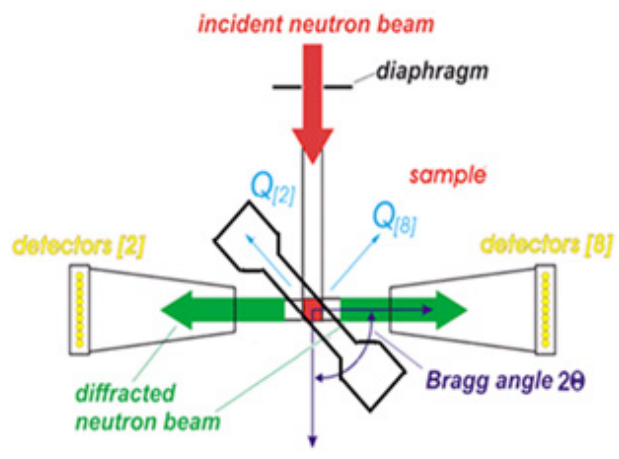

b) 


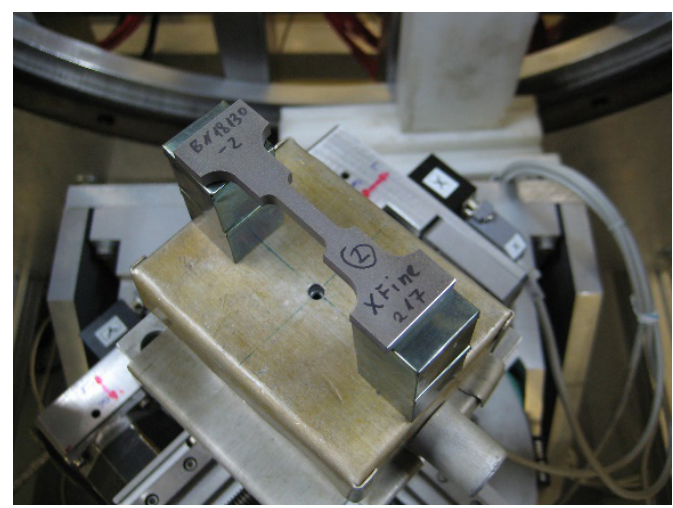

c)

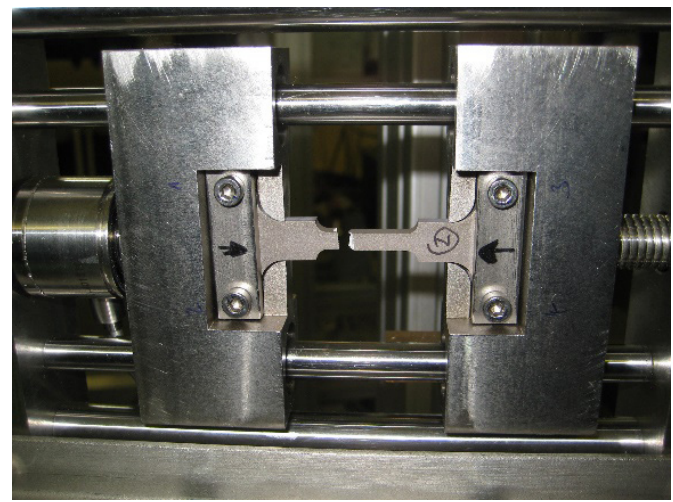

d)

Fig. 2 Dimensions of Al/SiC specimen: a), the geometry of the experiment b), $\mathrm{Al} / \mathrm{SiC}$ specimens: c) before experiment, d) after fracture in the tensile machine [3]

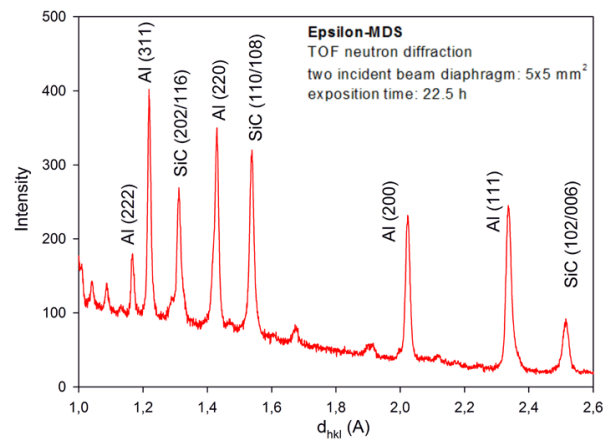

Fig. 3 The diffractogram obtained for Al/SiC composite on EPSILON diffractometer [3] 


\section{RESULTS ANALYSIS}

In the in situ tensile tests the relative lattice strains in the direction of the load $\left\langle\varepsilon_{11}\right\rangle_{\{\mathrm{hkl}\}}$ and in the transverse direction $\left\langle\varepsilon_{22}\right\rangle_{\{\mathrm{hkl}\}}$ were determined using eq. 14 [3]:

$$
\begin{aligned}
\left\langle\varepsilon_{11}\right\rangle_{\{h k l\}}= & \frac{\left\langle d_{L D}\right\rangle_{\{h k l\}}^{\Sigma}-\left\langle d_{L D}\right\rangle_{\{h k l\}}^{0}}{\left\langle d_{L D}\right\rangle_{\{h k l\}}^{0}} \\
& \text { and } \\
\left\langle\varepsilon_{22}\right\rangle_{\{h k l\}}= & \frac{\left\langle d_{T D}\right\rangle_{\{h k l\}}^{\Sigma}-\left\langle d_{T D}\right\rangle_{\{h k l\}}^{0}}{\left\langle d_{T D}\right\rangle_{\{h k l\}}^{0}}
\end{aligned}
$$

where: $\langle d\rangle_{\{h k l\}}^{\Sigma}$ and $\langle d\rangle_{\{h k l\}}^{0}$ are the interplanar spacings measured for a loaded (for a given applied stress $\Sigma_{11}$ ) and non-loaded sample (initial, i.e. for $\Sigma_{11}=0$ ) with the $\langle\ldots\rangle_{\{\text {hkl }}$ ) brackets denoting an average over the diffracting grains volume for a given reflection $h k l$. Indices LD and TD mean that the interplanar spacings were measured in the direction of the load and in the transverse direction, respectively. This methodology allowed obtaining the changes of lattice strains (eq. 14) for separate phases and for different $h k l$ 's reflections (in both phases) after determining the position of peaks for every stage of the sample deformation. Next, the values of strains in a given direction were used to calculate the stress values in both phases and for different $h \mathrm{kls}$. After using the weighted average, the mean macroscopic stress value could be obtained in relation to the macroscopic strain of the specimen.

The analysis and comparison of macrocurves for the hard state of A12124 alloy and the $\mathrm{Al} / \mathrm{SiC}$ composite (Fig. 4) allows to state that the significant role in the material hardening plays the addition of reinforcement to the composite. In both cases the same T6 thermal treatment was applied so the changes in composite macroscopic curve (comparing to the single phase alloy) can be explained by the addition of reinforcement particles. It can be observed that while the ultimate tensile strength of aluminum alloy is about $370 \mathrm{MPa}$, its value for the composite reaches much higher level of 650MPa. Moreover it was found that the experimental macroscopic curves were confirmed by the calculations of self-consistent model predictions. It should be emphasized that model predictions were performed assuming the same value of CRSS as previously for A12124 T6 alloy (the $\tau_{0 \mathrm{Al}}=120 \mathrm{MPa}$ was chosen in this case) [3]. 

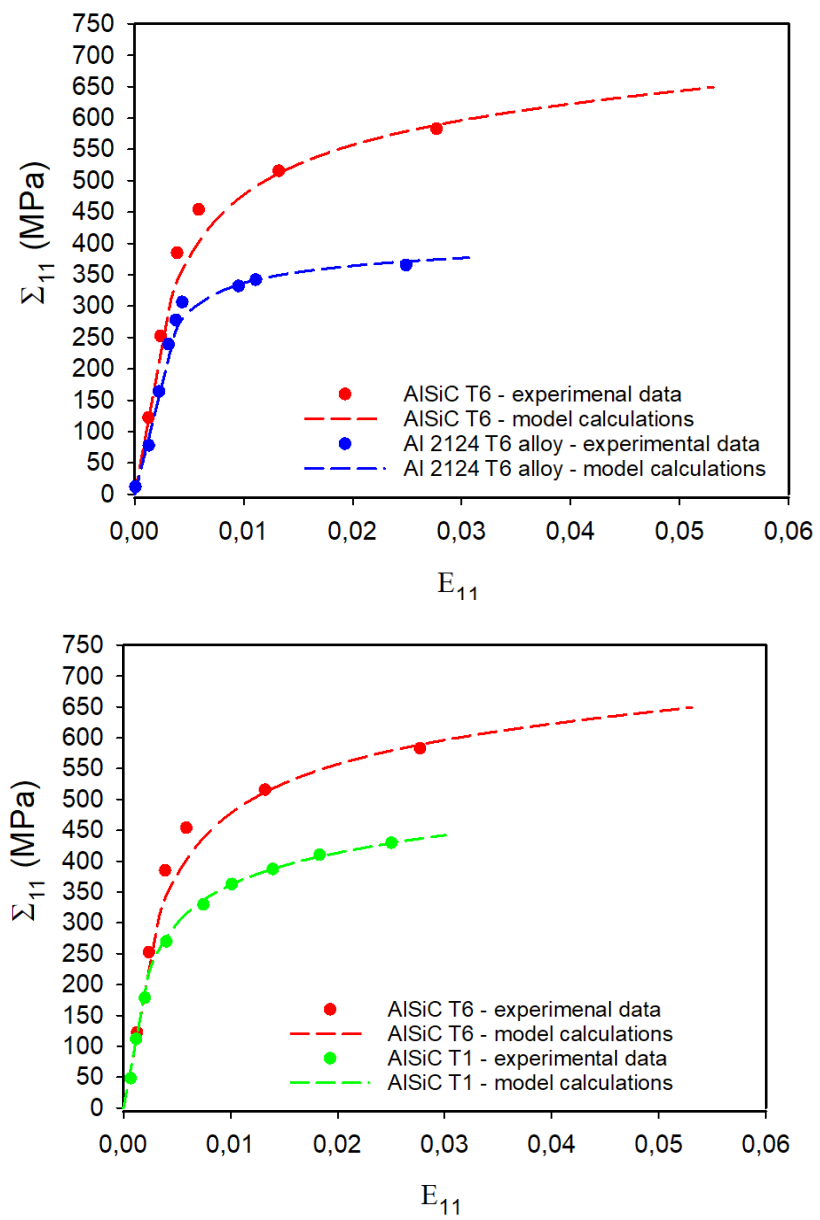

Fig. 4 Macroscopic dependence of macroscopic stress (after stabilization) vs. macroscopic strain for: a) single phase Al2124 T6 alloy and Al/SiC T6 composite (model predictions for T6 treatment: $\tau_{0 A l}=120 \mathrm{MPa}$ and $\mathrm{H}_{A l}=50 \mathrm{MPa}$ ), b) two types of composite after T1 and

T6 heat treatment (model predictions for T1 treatment: $\tau_{0 A l}=82 \mathrm{MPa}$ and $H_{A l}=50 \mathrm{MPa}$ )

When comparing the experimental results for the composites after applying a different heat treatment, it can be seen that the yielding point for $\mathrm{Al} / \mathrm{SiC} \mathrm{T} 1$ and its ultimate tensile strength are obviously different than for $\mathrm{Al} / \mathrm{SiC}$ in $\mathrm{T} 6$ - their values are about $200 \mathrm{MPa}$ and $450 \mathrm{MPa}$, respectively. As the reinforcement particles are the same in both types of the composite $(17.8 \%$ of $\mathrm{SiC}$ particles with a size of $0.7 \mu \mathrm{m}$ ) the appearance of different macroscopic curves for this material can be caused only by the changes of the aluminum matrix microstructure due to a different thermal treatment. Indeed, in the case of the $\mathrm{Al} / \mathrm{SiC} \mathrm{T} 1$ material, the best fit of the model calculations was obtained for $\tau_{0 \mathrm{Al}}=82 \mathrm{MPa}, \mathrm{H}_{\mathrm{Al}}=50 \mathrm{MPa}$, i.e. 
the $\mathrm{Al}$ matrix is softer compared to the alloy after the $\mathrm{T} 6$ treatment. This effect can be explained by the size of precipitates (mainly $\mathrm{Cu}-\mathrm{Al}-\mathrm{Mg}$ ) created during thermal treatments in the $\mathrm{Al}$ matrix. The $\mathrm{T} 6$ process (quenching and artificial ageing) leads to much smaller precipitates compared to these after T1 treatment (slow cooling and natural ageing). As mentioned above, the small size of precipitates (after the $\mathrm{T} 6$ treatment) leads to the precipitation hardening, while the strengthening effect is less significant for large precipitates (after the T1 treatment) [3].

\section{CONCLUSIONS}

Thanks to the methodology applied the hardening mechanisms and strengthening type could be observed, illustrated and characterized. The comparison of the results for $\mathrm{Al} / \mathrm{SiC}$ and aluminum alloy samples subjected to the $\mathrm{T} 6$ treatment nearly the same plastic behavior was found for the aluminum phase. In this case, the overall stress was much higher in the case of composite, during whole tensile test. This type of increase in stress values is characteristic for composites and is due to the stress being localized in the reinforcement. This effect is well predicted by the model used. The second comparison was made for the $\mathrm{Al} / \mathrm{SiC}$ composite subjected to different treatments: $\mathrm{T} 1$ and $\mathrm{T} 6$ to present the influence of heat treatment of different types on the hardening of the composite and to find the reason for this phenomenon. It was observed that stresses in the composite are higher for the material subjected to the $\mathrm{T} 6$ treatment. The Al-matrix is harder in this material, causing higher overall stress. This can be explained by a smaller size of precipitates in the $\mathrm{Al}$ matrix after the $\mathrm{T} 6$ process (quenching and artificial ageing) leading to locking dislocations and important hardening during the plastic deformation. Comparison of the elastoplastic self-consistent model with measured lattice strains allowed to find out the micro-mechanical properties of the 2124 aluminum alloy and the $\mathrm{Al} / \mathrm{SiC}$ composite, i.e. critical resolved shear stress and hardening parameter for aluminum for both heat treatments. By using theoretical calculations and diffraction results, the roles of the matrix and reinforcement in composite hardening were described.

\section{ACKNOWLEDGEMENTS}

The authors wish to thank the Frank Laboratory of Neutron Physics (JINR Dubna, Russia) for providing the neutrons. The neutron experiments were supported by the Polish-JINR Programme 2017 (item 24), and the operation of the EPSILON diffractometer was supported by the Federal Ministry for Education and Research in Germany. 


\section{REFERENCES}

[1] A. Baczmański, "Stress fields in polycrystalline materials studied using diffraction and self-consistent modeling," postdoctoral dissertation, AGH - University of Science and Technology, Kraków, 2005.

[2] A. Baczmański and C. Braham, "Elastoplastic properties of duplex steel determined using neutron diffraction and self-consistent model," Acta Materialia, vol. 52, no. 5, pp. 1133-1142, Mar. 2004.

[3] E. Gadalińska, "Micromechanical properties and stresses in two-phase polycrystalline materials studied using diffraction and self-consistent model," Doctoral Thesis, AGH - University of Science and Technology, Kraków, 2018.

[4] A. Maciejny, "Mechanizm umocnienia kompozytów," Krzepnięcie metali i stopów. Krystalizacja i własności kompozytów odlewanych., vol. 7, pp. 335-353, 1984.

[5] R. J. McElroy and Z. C. Szkopiak, "Dislocation-Substructure-Strengthening and Mechanical-Thermal Treatment of Metals," International Metallurgical Reviews, vol. 17, no. 1, pp. 175-202, Jan. 1972.

[6] M. Rozmus-Górnikowska, "Umocnienie wydzieleniowe stopu $\mathrm{Al} \mathrm{z} \mathrm{Cu}+$ umocnienie stali," Kraków.

[7] T. W. Clyne and P. J. Withers, An Introduction to Metal Matrix Composites. Cambridge University Press, 1993.

[8] R. J. Arsenault and N. Shi, "Dislocation generation due to differences between the coefficients of thermal expansion," Materials Science and Engineering, vol. 81, pp. 175-187, Aug. 1986.

[9] R. J. Arsenault, L. Wang, and C. R. Feng, "Strengthening of composites due to microstructural changes in the matrix," Acta Metallurgica et Materialia, vol. 39, no. 1, pp. 47-57, Jan. 1991.

[10] S. B. Prabu, L. Karunamoorthy, S. Kathiresan, and B. Mohan, "Influence of stirring speed and stirring time on distribution of particles in cast metal matrix composite," Journal of Materials Processing Technology, vol. 171, no. 2, pp. 268-273, Jan. 2006.

[11] K. Suryanarayanan, R. Praveen, and S. Raghuraman, "Silicon carbide reinforced aluminium metal matrix composites for aerospace applications: a literature review," International Journal of Innovative Research in Science, Engineering and Technology, vol. 2, no. 11, pp. 6336-6344, 2013.

[12] S. H. Avner, Introduction to physical metallurgy. New York: McGraw-Hill, 1964.

[13] Y. Lakhtin and N. Weinstein, Engineering physical metallurgy. University Press of the Pacific, 2000.

[14] M. M. Boopathi, K. P. Arulshri, and N. Iyandurai, "Evaluation of mechanical properties of aluminium alloy 2024 reinforced with silicon carbide and fly 
ash hybrid metal matrix composites," American Journal of Applied Sciences, vol. 10, no. 3, pp. 219-229, 2013.

[15] S. V. S. Narayana Murty, B. Nageswara Rao, and B. P. Kashyap, "On the hot working characteristics of 6061Al-SiC and 6061-A12O3 particulate reinforced metal matrix composites," Composites Science and Technology, vol. 63, no. 1, pp. 119-135, Jan. 2003.

[16] M. E. Fitzpatrick, "A study of the effects of a quench residual stress field on fatigue in an Al/SiCp metal matrix composite," University of Cambridge, 1995.

[17] F. Xu, J. Zhang, Y. Deng, and X. Zhang, "Precipitation orientation effect of 2124 aluminum alloy in creep aging," Transactions of Nonferrous Metals Society of China, vol. 24, no. 7, pp. 2067-2071, Jul. 2014. 